\title{
ASPECTS OF QUALITY EVALUATION IN AVIATION MAINTENANCE
}

\section{A. Gališanskis}

\author{
Antanas Gustaitis Aviation Institute of Vilnius Gediminas Technical University. \\ E-mail:a_galisanskis@hotmail.com \\ Received 0723 2004, accepted 07102004
}

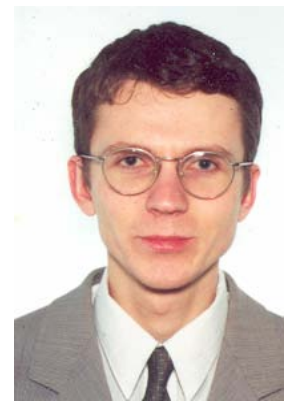

Artūras GALIŠANSKIS was born in 1975.

Education: Vilnius Gediminas Technical University, Antanas Gustaitis Aviation Institute: Bachelor's Degree in Mechanical Science (1998), Master's Degree in Mechanical Science (2000). At present - Doctoral studies at Vilnius Gediminas Technical University Antanas Gustaitis Aviation Institute, Rodūnès kelias 30, LT-2038, Vilnius, phone (+370) 67607273

Publications: 3 scientific papers.

Abstract: This article deals with the review of the main parameters and assessment of a quality system. A quality assurance system and its management are of great importance to an aviation organization whether it is large or small. The final task of the quality system is to ensure the technical aircraft maintenance system at a high level of quality, to ensure airworthiness of the aircraft. In our days Total Quality Management (TQM), as a new philosophy, is gaining power in civil aviation. Seeking quality is vital for maintenance organization for such reasons as the survival of the organization and competitiveness in the market. TQM is directly connected with the ISO 9000:2000 series standard implementation and involves many other parameters such as the qualifications of personnel and training. As an instrument for control, an audit, done by themselves or by an outside company, is indicated.

During civil aviation maintenance organization quality evaluation performance, quality and safety parameters were indicated using FAA and JAA requirements and ISO 9000 series for maintenance organizations. All parameters presented in the appendix of this article. Since one of the most significant things in a quality system is the audit, statistical methods to evaluate the results of an audit are presented in the article.

Keywords: quality, total quality management, quality and safety parameters, audit, quality improvement, statistical analysis.

\section{Introduction}

It is no secret that if you want to survive in business today, you must pay a lot of attention to quality. If users or customers needs are not satisfied, you will not sell any product or service. There is a direct relationship between quality and customer satisfaction: the higher the quality of the product, the higher the level of customer satisfaction with the product or service. So this means that an organization has to seek high quality for such reasons: 1) survival of organization, 2) competition for market share, 3) ambition to be among the best organizations [3].

The concept of quality is very wide and is described differently. ISO 9000:2000 describes quality as a "degree to which a set of inherent characteristics fulfils requirements". Otherwise, quality is customer satisfaction.

Seeking quality requires thorough and hard work, investing a lot into the creation of a quality system, monitoring, and continuous improvement of the quality system.

\section{Total quality management and quality improvement}

As mentioned in the introduction, if an organization wants to stay in business, it must seek quality - perform quality services, manufacture quality products, etc. The easiest and most efficient means to reach this is by using total quality management. Total quality management (TQM) is revolutionary in quality philosophy. All organization's members are taking part in TQM process, satisfying internal and external customer's needs and using continual quality improvement. Continual quality improvement is determined by some standards (such as ISO 9000 series): the organization must plan and implement the monitoring, measurement, analysis, and improvement processes needed to demonstrate conformity of the product, to ensure conformity of the quality management system and to continually improve the effectiveness of the quality management system [9]. 


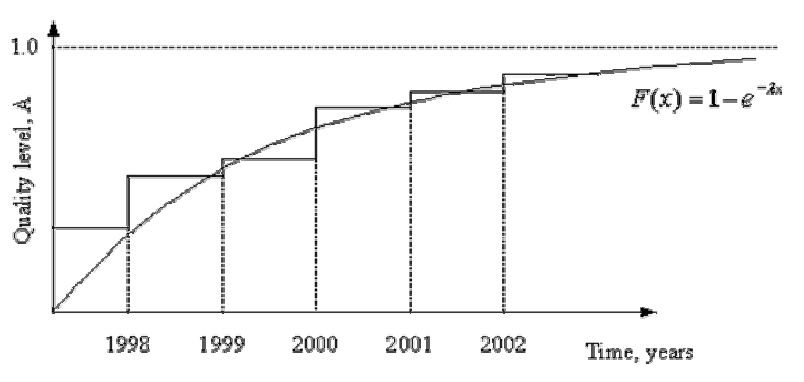

Fig 1. The principles of continuous quality improvement

One of the main goals of TQM is quality improvement, and in such cases the same TQM is called continuous quality improvement [3]. Continuous quality improvement is an endless process (see figure 1) having an exponential law, where quality level can be assessed by minimum of findings fixed during the audit procedures. So-called Deming Cycle (PDCA: Plan-DoCheck-Act) represents the process of continuous quality improvement - see Figure 2.

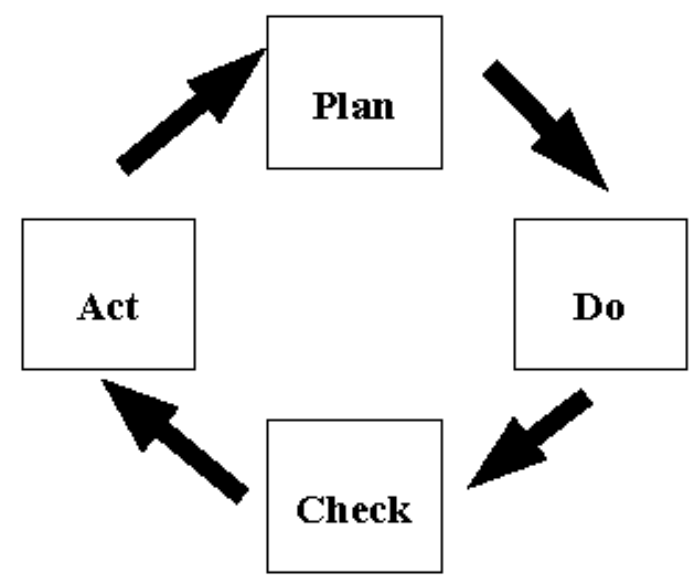

Fig 2. Deming cycle

Quality improvement can be reached using continuous improvement, corrective actions, and preventive actions. Continuous improvement is performed using quality policy, quality objectives, quality data analysis, quality audits, etc. Corrective and preventive actions also belong to continual improvement. The difference between corrective and preventive action is that corrective actions are allocated to solve noncompliance and its origin in order to prevent reoccurrence of this noncompliance. Preventive actions are allocated to eliminate the origin of possible and potential noncompliance. Quality audits help to provide data for those actions.

\section{Quality and safety parameters}

Quality can be evaluated with some parameters that can be chosen by the type of activity. In order to find those parameters, we will use current civil aviation requirements and results will be presented in Appendix 1 [5-8, 10-12].

Of course, implementation of all those parameters would require a lot of financial resources that an organization, just starting operations, does not always have. So organization may choose to control only the main and most significant parameters in the beginning of operations.

One of the most important quality and safety parameters is the performance of quality audits in the organization. Those audits (internal or external) monitor the quality system of organization and give the information about noncompliance to requirements. The audit system will be detailed in the next chapter.

\section{Quality assessment by audit}

Auditing is the one of the means for quality assessment in industry. An organization can order an audit from other organizations if it does not have its own audit personnel. Such an audit is called an outside audit. If an organization is big enough and has own quality assurance department, this division performs an audit. If an organization is small, the heads of departments can fulfill the task of auditing after they are trained and acquire the relevant knowledge.

The maintenance organizations of civil aviation act according to the special requirements. Lithuania, as a member of JAA must comply with a JAR-145 requirements. Audits are performed to determine whether an organization complies with those requirements (Figure 3). This figure shows that at first, maintenance organization exposition (MOE) will be checked in order to compare MOE procedures with requirements in force (FAA, JAA, EASA, etc.). If MOE procedures do not comply with requirements, noncompliance must be rectified. If MOE procedures are written well, the application of those procedures in an organization's everyday activities must be checked.

Every organization consists of smaller subdivisions performing special activities, so, the purpose of the audit is to check a compliance of their activity to the requirements. Usually, the technical organization consists of the department of maintenance, department of engineering support, quality assurance department, procurement department, etc.

Noncompliance is fixed by the findings. There are three groups of findings used in civil aviation: findings of the first, second, and the third level. The quality system of the organization can be assessed according to all the findings in general or according to the each separate type of findings.

When analyzing the results from the preceding year, they are usually compared to the results of the year before. If the number of findings decreases, it does not mean that the quality system is getting better. The most important is the number of the findings of the first level. The first level findings are given when it is stated that one of the departments has violated requirements, therefore influencing airworthiness. For example, an instrument not approved by the documentation of the producer was used to repair the wheels of the aircraft.

One example of the results of an internal audit of one department of an organization's is presented in Table 2. 


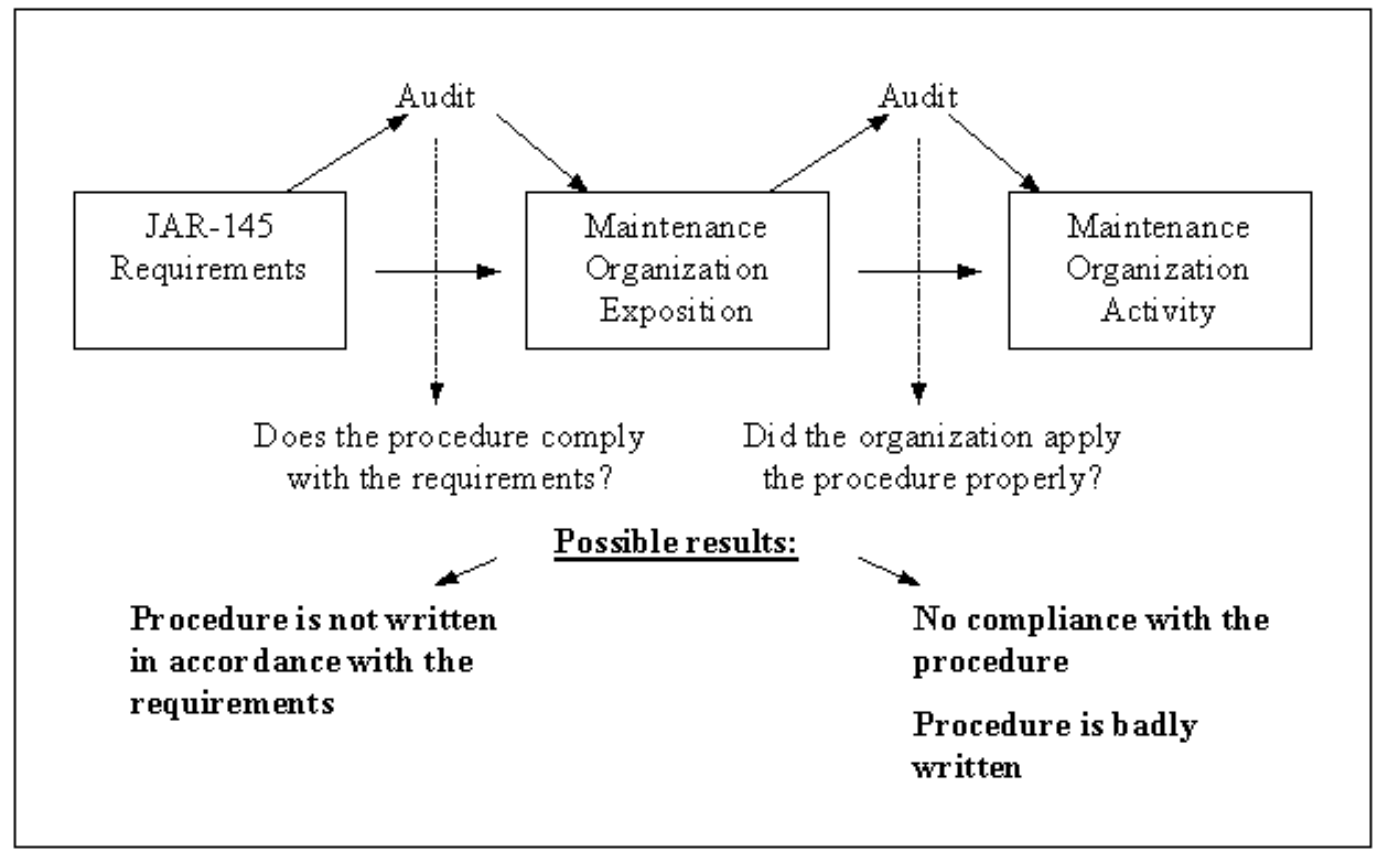

Fig 3. Checking of the compliance of organization with the requirements

Table 2. The results of the YYY organization department internal audits

\begin{tabular}{|c|c|c|c|c|c|c|c|c|c|c|c|c|}
\hline & \multicolumn{12}{|c|}{ Audits } \\
\hline & 1 & 2 & 3 & 4 & 5 & 6 & 7 & 8 & 9 & 10 & 11 & 12 \\
\hline 1st level findings & 0 & 0 & 0 & 0 & 0 & 0 & 0 & 0 & 3 & 0 & 1 & 4 \\
\hline 2nd level findings & 4 & 3 & 3 & 2 & 0 & 1 & 5 & 4 & 5 & 3 & 1 & 1 \\
\hline 3rd level findings & 1 & 1 & 1 & 0 & 3 & 2 & 1 & 1 & 4 & 0 & 0 & 0 \\
\hline Sum of all findings & 5 & 4 & 4 & 2 & 3 & 3 & 6 & 5 & 12 & 3 & 2 & 5 \\
\hline
\end{tabular}

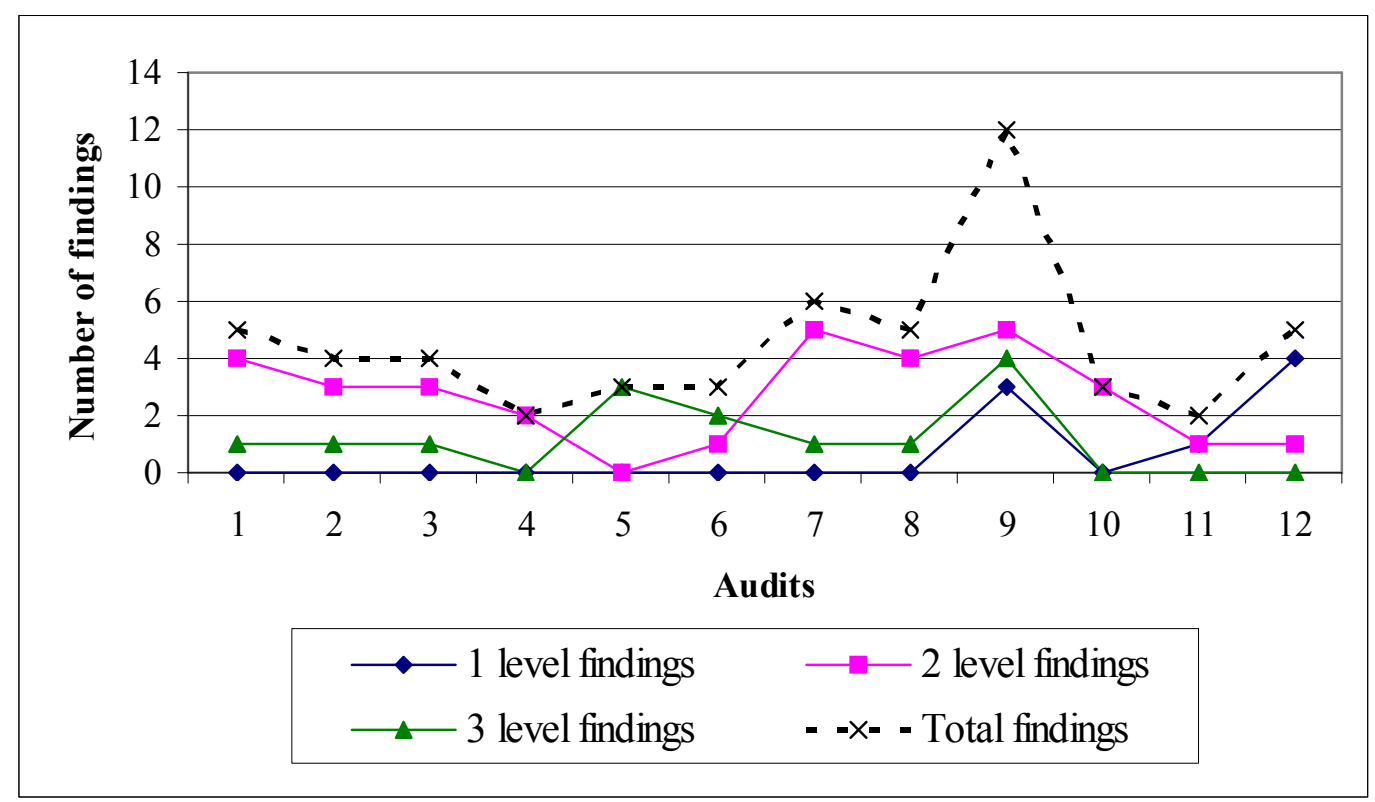

Fig 4. The chart of organization's YYY department internal audits results

During these audits, the checklist contained 52 items (parameters) that were evaluated.

The results of audits are presented in Figure 4. The maximum number of notices was declared during the ninth audit. The maximum number of findings of the first level was declared during the last, twelfth registered audit. 
If we review the results of audits of the particular department in organization YYY (Table 3, Figures 5 and 6 ), we can see that the reasons for level 1 finding are almost equal in their nature, but for level 2 findings, the largest share of noncompliance is due to documentation problems (completion, update, availability of certificates, etc.). Problems with tools and equipment (not marked, not working, etc.) were the second most common and problems with storage (shelf life exceeded, storage of serviceable and unserviceable items together, etc.) were on the third place.

Table 3. Reasons for findings of level 1 and level 2 in organization YYY

\begin{tabular}{|l|c|}
\hline \multicolumn{1}{|c|}{ Reasons for findings } & $\begin{array}{c}\text { Number of } \\
\text { findings }\end{array}$ \\
\hline Level 1 findings: & 2 \\
Maintenance procedures & 2 \\
Documentation & 2 \\
Storage & 1 \\
Environmental standards & 1 \\
Calibration & \\
\hline Level 2 findings: & 4 \\
Storage & 3 \\
Calibration & 6 \\
Tools and equipment & 15 \\
Documentation & 1 \\
Environmental standards & 2 \\
Material & 1 \\
Work procedures & \\
\hline
\end{tabular}

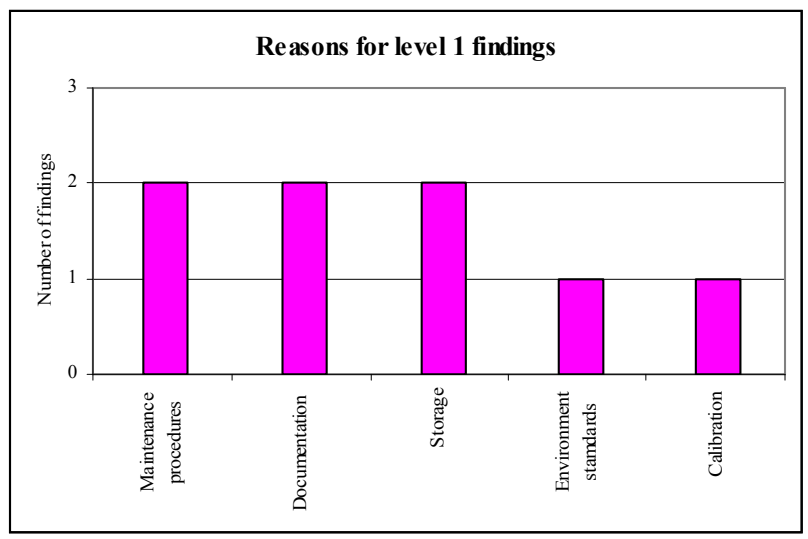

Fig 5. The reasons for level 1 finding in organization YYY

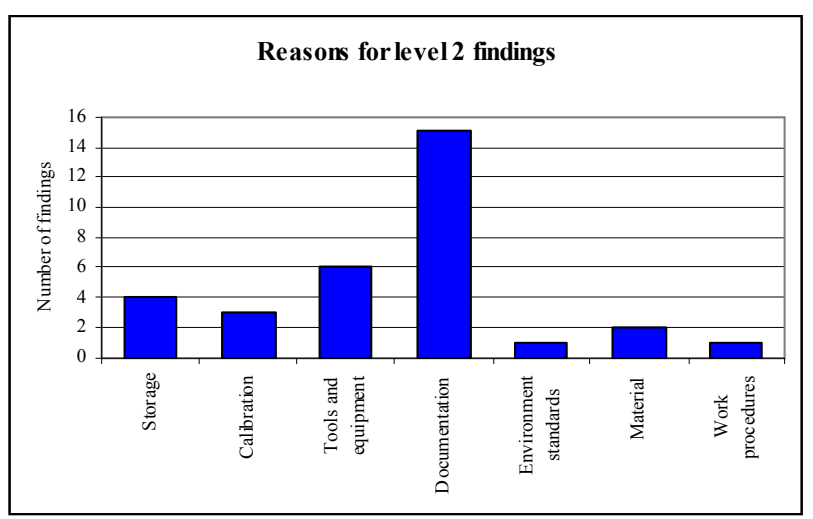

Fig 6. The reasons for level 2 findings in organization YYY
For the clear view of level 2 findings and percentages, Pareto analysis will be used. It is particularly useful in dealing with chronic problems because it helps one to decide which of several chronic problems to attack [2]. As can be seen from Figure 7, the main problems to deal with are documentation, tools and equipment, and storage. Three main problems contain $78.13 \%$ of all level 2 findings. A quality assurance system must therefore focus its attention on solving these three problems. As one of most significant tools in solving documentation problems, an organization can use training and qualification reassessment.

The reasons for a fall in the level of quality must be searched for when analyzing the activity of the department since its range of activities is quite wide. The actions taken to eliminate the limitations detected depend on the size of the organization, on the current situation and circumstances, and, on the traditions of decisionmaking in organization (of course, private organizations deal with them better than state owned organization). Nevertheless, the actions taken to eliminate the flaws must be effective enough to ensure that the reasons for their appearance do not have the possibility to re-appear. These reasons must be eliminated and preventive measures must be taken after an analysis of the style of work in the department.

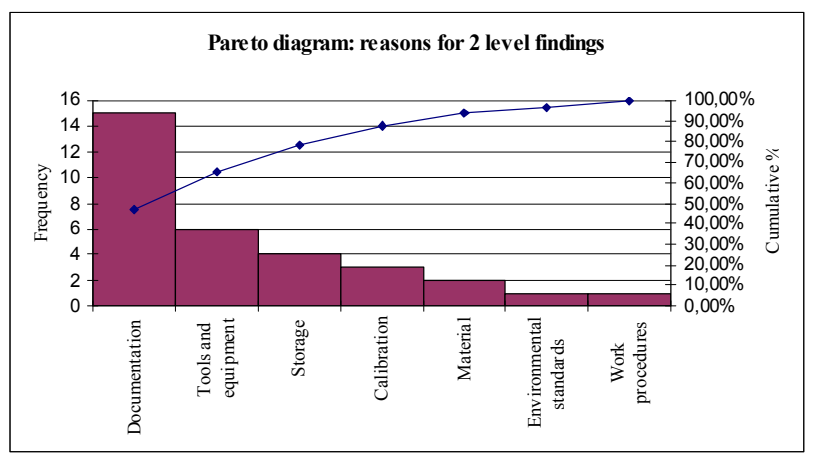

Fig 7. Pareto diagram reasons for level 2 findings in organization YYY

Figure 4 reflects total sum of findings only, and the 52 parameters that were checked during audits and associated with work procedures, working with instruments, tools, equipment, training, etc., were not rated in this chart. It is also important to know how many parameters were checked evaluate the level of quality in a department or a whole organization. In the next section we will apply statistical analysis (mean, standard deviation) to evaluate the results of an audit and demonstrate it graphically.

\section{Possibility of using statistical methods to evaluate quality}

The use of statistical methods can greatly improve evaluation and processing of the results of an audit. The use of statistical techniques can help understand variability and thereby help organizations solve problems, and improve effectiveness and efficiency [10]. 
We will consider that the results of an audit are random events and normal distribution (with mean $\bar{x}$ and standard deviation s) can be used for the purposes with sufficient accuracy.

If the probability of every random event is equal, then $\bar{x}$.

$$
\bar{x}=\frac{\sum_{i=1}^{n} x_{i}}{n} \text {; }
$$

where $\quad \mathrm{n}$ - number of findings; $\mathrm{x}_{\mathrm{i}}-i$ - times single value

Standard deviation $S$ will be:

$$
s=\sqrt{\frac{\sum_{i=1}^{n}\left(x_{i}-\bar{x}\right)^{2}}{n-1} ;}
$$

These formulas and data from table 2 were used to process the results of an audit $(n=52)$. For these parameters that did not produce noncompliance, $x_{i}=0$. Results are displayed in table 4 and figure 8.

Based on the results, we can prepare audit control charts using such parameters as Center Line (CL), Upper Control Limit (UCL), and Lower Control Limit (LCL) [1]. A control chart shows real process, its history, and it shows deviations from process or process violations timely [1].

For the preparation of an audit control chart, we must identify parameters CL, UCL, and LCL.

CL or mean of means will be:

$$
C L=\bar{q}=\frac{\sum_{i=1}^{N} \overline{x_{i}}}{N}
$$

where $\quad \mathrm{N}-$ number of audits (12 in this case);

$$
\bar{x}_{\mathrm{i}}-i \text { - times mean value }
$$

UCL and LCL will be:

$$
U C L(L C L)=\bar{q} \pm 3 \sqrt{\frac{\sum_{i=1}^{N}\left(\overline{x_{i}}-\bar{q}\right)^{2}}{N-1}}
$$

Formula 4 contains number 3 , which means $\bar{x}_{i}$ values goes to interval $\pm 3 \sigma$ with a probability of $99.7 \%$. Results of calculations are presented in Table 4.

Table 4. The results of statistical evaluation of an internal audit in organization YYY

\begin{tabular}{|c|c|c|c|c|}
\hline $\begin{array}{c}\text { Audits } \\
\text { No }\end{array}$ & $\bar{x}_{\text {1 level }}$ & $\bar{x}_{\text {2 level }}$ & $\bar{x}_{\text {3 level }}$ & $\bar{x}_{\Sigma}$ \\
\hline 1 & 0 & 0,0769 & 0,0192 & 0,0962 \\
\hline 2 & 0 & 0,0577 & 0,0192 & 0,0769 \\
\hline 3 & 0 & 0,0577 & 0,0192 & 0,0769 \\
\hline 4 & 0 & 0,0385 & 0 & 0,0385 \\
\hline 5 & 0 & 0 & 0,0577 & 0,0577 \\
\hline 6 & 0 & 0,0192 & 0,0385 & 0,0577 \\
\hline 7 & 0 & 0,0962 & 0,0192 & 0,1154 \\
\hline 8 & 0 & 0,0769 & 0,0192 & 0,0962 \\
\hline 9 & 0,0577 & 0,0962 & 0,0769 & 0,2308 \\
\hline 10 & 0 & 0,0577 & 0 & 0,0577 \\
\hline 11 & 0,0192 & 0,0192 & 0 & 0,0385 \\
\hline 12 & 0,0769 & 0,0192 & 0 & 0,0962 \\
\hline \begin{tabular}{c} 
Mean of \\
\hline$q$
\end{tabular} & $\mathbf{0 , 0 1 2 8 2 1}$ & $\mathbf{0 , 0 5 1 2 8 2}$ & $\mathbf{0 , 0 2 2 4 3 6}$ & $\mathbf{0 , 0 8 6 5 3 8}$ \\
\hline $\begin{array}{c}\text { Standard } \\
\text { deviation s }\end{array}$ & $\mathbf{0 , 0 2 6 3 5 9}$ & $\mathbf{0 , 0 3 2 1 1}$ & $\mathbf{0 , 0 2 4 3 7 1}$ & $\mathbf{0 , 0 5 1 5 3 6}$ \\
\hline UCL & $\mathbf{0 , 0 9 1 8 9 9}$ & $\mathbf{0 , 1 4 7 6 1 1}$ & $\mathbf{0 , 0 9 5 5 5}$ & $\mathbf{0 , 2 4 1 1 4 8}$ \\
\hline LCL & $\mathbf{- 0 , 0 6 6 2 6}$ & $\mathbf{- 0 , 0 4 5 0 5}$ & $\mathbf{- 0 , 0 5 0 6 8}$ & $\mathbf{- 0 , 0 6 8 0 7}$ \\
\hline
\end{tabular}

As can be seen from the Lower Control Limit calculations, all values are negative. So all of them we will equate to 0 .

Now we prepare an audit control chart for level 2 findings where every audit means, CL and UCL will be indicated. The results are displayed in Figure 9.

As can be seen, no mean of level 2 findings reached UCL. Data from the previous period should be used to calculate UCL. If a quality system continuously improves, UCL will decrease.

It must be mentioned that statistical analysis will be effectively applied only when an organization performs many audits. If you want to perform statistical analysis you should have enough data. Otherwise the results of analysis can be incorrect or inadequate. When talking about audit results and analysis of audits, statistical analysis cannot give answers with 100\% accuracy, but it can be used as a tool. 


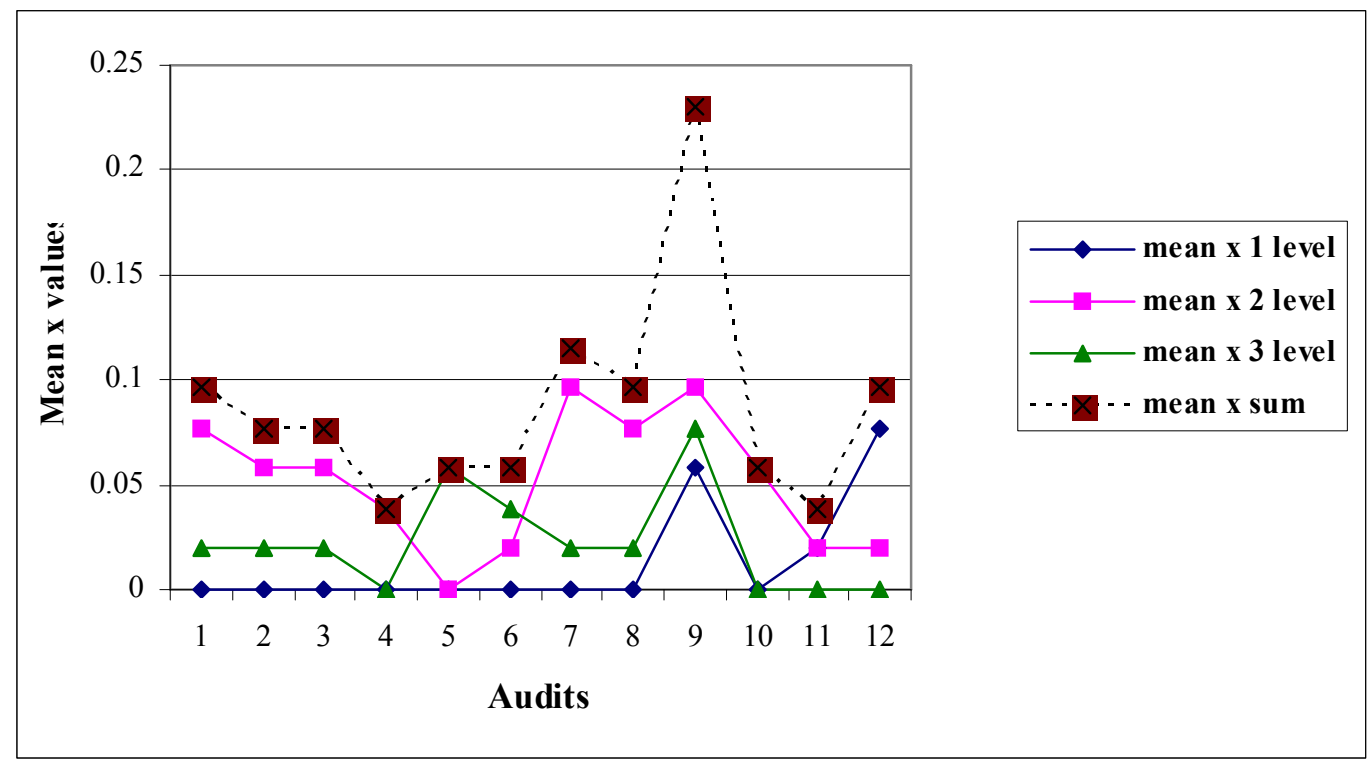

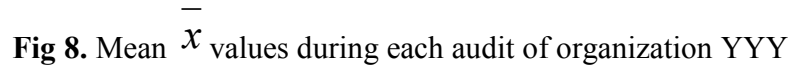

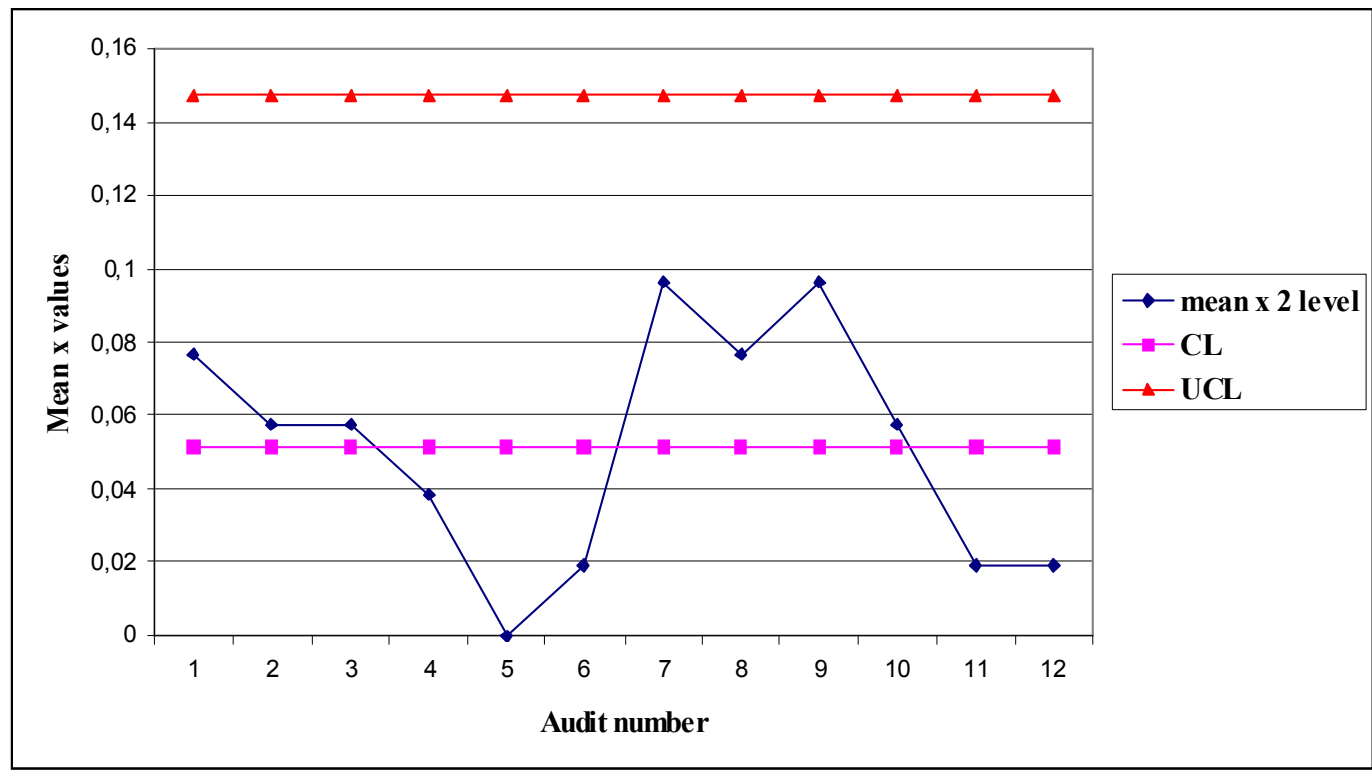

Fig 9. Audit Control Chart for level 2 findings

\section{Conclusions}

1. The continuous development of a quality assurance system mostly depends on the analysis of the results of previous audits. These results are to be compared with the relevant period under analysis.

2. An important feature of analysis is a concentration on the areas where no progress has been made or the results are worse than previous parameters.

3. The procedures that follow analysis are such: the writing of new procedures and correction of the old ones; organization of personnel training; reassessment of qualifications.
4. In case of organizational problems, the personal of an organization must be changed, etc.

5. Statistical evaluation of quality parameters gives ability to perform deeper analysis of deficiencies and can speed up preventive actions and any improvements of quality system.

6. It is always better to apply preventive actions than fix problems that occur. This way a company can save money, its reputation, and its market share.

7. Statistical analysis can be an advantage in solving problems and monitoring a quality system. 
Appendix 1. Quality and safety parameters that defines maintenance organization

\section{Work environment}

1.1. Sufficiency of facility

1.2. Appropriate work environment

1.3. Separate working places

1.4. Appropriate storage conditions for components, material, equipment, and tools

\section{Personnel}

2.1. Acceptance of management personnel to the Authority (see 6.5)

2.2. Responsibility of Accountable manager for safety and quality policy

2.3. Appointment of person, responsible for the quality system (see 6.4)

2.4. Human factor

2.4.1. Physical condition of personnel

2.4.2. Training on human factors and human performance issues (see 2.6.5.2)

2.4.3. Minimizing and detection of maintenance errors (see 8.11)

2.4.4. Shift handover (see 7.10)

2.4.5. Communication with customers

2.4.6. Knowledge of personnel about their activity

2.5. Continuous maintenance experience of personnel

2.6. Qualification and training

2.6.1. Suitability of personnel for work performed

2.6.2. Sufficient knowledge about aircraft maintained and / or aircraft components and related company procedures (training, examination)

2.6.3. Ability of maintenance personnel to understand documentation of aircraft manufacturer

2.6.4. Evaluation of qualification of personnel

2.6.5. Training of personnel

2.6.5.1. Continuing education

2.6.5.2. Training on human factors and human performance issues (see 2.4.2)

2.6.5.3. Type training

2.6.5.4. Basic training

2.6.6. Conformity of qualification of personnel to requirements

\section{Material}

3.1. Evaluation of suppliers

3.2. Control of sub-contractors

3.3. Incoming inspection

3.4. Conformity of product purchased to requirements

3.5. Hard time components control

4.1. Commitment of resources to quality system

\section{Resources}

\section{Records}

5.1. Personnel qualification, experience data recording and storage

5.2. Notification of approved maintenance data inaccuracies to the author

5.3. Completion of documents during and after the work

5.4. Work and maintenance records and control

5.5. Calibration records

5.6. Storage of

5.7. Traceability maintenance records

\section{Management procedures}

6.1. Division of authority and responsibility

6.2. Protection of customer property

6.3. Avoiding falsification of maintenance records

6.4. Appointment of person, responsible for the quality system (see 2.3)

6.5. Acceptance of management personnel to the Authority (see 2.1)

7.1. Calibration procedures

7. Work quality

7.1.1. Performance of calibration

7.1.2. Calibration of tools and equipment

7.1.3. Calibration of measuring tools

7.2. Following repair and maintenance practices 
7.3. Working with maintenance data procedures

7.3.1. Having and using valid and appropriate maintenance data

7.3.2. Availability of maintenance data to personnel

7.3.3. Continual update of maintenance data

7.4. Maintenance procedures

7.4.1. Maintenance documentation (MOE, Quality Manual, etc.) (see 8.10)

7.4.2. Marking MEL items in aircraft cabin

7.4.3. Reflection of changing aircraft parameters in technical documentation

7.4.4. Maintenance of aircraft / aircraft components with permission only

7.4.5. Release to service procedures

7.4.5.1. Aircraft / aircraft component maintenance certification before release to service

7.4.5.2. Reference to incomplete work in certificate of release to service

7.4.5.3. Certificate of release to service not issued if condition unairworthy

7.4.6. Elimination of defects affecting airworthiness

7.4.7. Performance of maintenance in accordance with approved maintenance program

7.5. Maintenance documentation control

7.6. Performance of continuous airworthiness requirements

7.7. Review of product requirements

7.8. Product monitoring and measurement

7.9. Product marking

7.10. Shift handover (see 2.4.4)

7.11. Planning procedures

7.11.1. Personnel planning

7.11.1.1. Adequacy of personnel for performed work

7.11.1.2. Assessment of human performance when planning work

7.11.1.3. Establishment of personnel function requirements

7.11.2. Availability of tools, equipment, and material

7.11.3. Personnel, tools, equipment, material, maintenance data, and facilities planning

7.11.4. Planning of continuing education

7.11.5. Quality procedures planning

7.11.5.1. Quality management system planning

7.11.5.2. Quality audit program planning

7.11.5.3. Establishment of safety and quality policy and quality objectives

7.11.6. Establishment of product requirements

7.11.7. Establishment of maintenance procedures

8.1. Quality system: quality assurance and control

8.2. Internal quality audit

8.3. Monitoring and measurement of quality process

8.4. Quality meetings

8.5. Application of statistical methods

8.6. Inspection

8.7. Process approach in quality system (PDCA)

8.8. Reporting

8.8.1. Reporting system regarding condition of unairworthiness

8.8.2. Reporting system regarding events that have influence on airworthiness

8.9. Maintenance documentation (MOE, Quality Manual, etc.) (see 7.4.1)

8.10. Involvement of maintenance organization personnel in quality system

8.11. Minimizing and detection of maintenance errors (see 2.4.3)

8.12. Improvement of quality system

8.12.1. Analysis

8.12.1.1. Review of quality management system

8.12.1.2. Self analysis

8.12.1.3. Analysis of quality data

8.12.1.4. Analysis of effectiveness of approved maintenance program (reliability program)

8.12.2. Continual improvement

8.12.3. Corrective actions

8.12.4. Preventive actions

8.12.5. Change of maintenance procedures and instructions for purposes of improvement 


\section{References}

1. Adomėnas V. Statistiniai kokybès valdymo metodai. - Kaunas: Technologija, 2000. - 253 p.

2. Amsden R.T., Buttler H.E., Amsden D.M. SPC Simplified: Practical Steps to Quality. - New York: Quality Resources, 1986. - 262 p.

3. Barczyk C.C. Visuotinès kokybès vadyba. - Vilnius: Eugrimas, 1999. - P. 256.

4. JAA. Joint Aviation Requirements JAR-66 (CERTIFYING STAFF MAINTENANCE), Issue 1. 1998-04-03.

5. JAA. Joint Aviation Requirements JAR-145 (APPROVED MAINTENANCE ORGANIZATION), Amendment 5. 2003-01-01.
6. JAA. JAR-OPS 1 Subpart $M$ (AEROPLANE MAINTENANCE), Amendment 6. 2003-08-01.

7. FAA. FAR CFR 14 Part 43 (MAINTENANCE, PREVENTIVE MAINTENANCE, REBUILDING, AND ALTERATION).

8. FAA. FAR CFR 14 Part 145 (REPAIR STATIONS).

9. Medekšas H. Gaminių kokybė ir patikimumas. Kaunas: Technologija, 2003. - 279 p.

10. Quality management systems - Fundamental and vocabulary (ISO 9000:2000).

11. Quality management systems - Requirements (ISO 9001: 2000). 